\title{
Innovation in Biomedical Engineering Education During the COVID-19 Pandemic
}

\author{
Toh Yen Pang ${ }^{1}$, Frank Feltham ${ }^{2}$ \& Elena Pirogova ${ }^{1}$ \\ ${ }^{1}$ School of Engineering, RMIT University, Melbourne, Victoria, Australia \\ ${ }^{2}$ School of Industrial Design, RMIT University, Melbourne, Victoria, Australia \\ Correspondence: Toh Yen Pang, School of Engineering, RMIT University, Melbourne, Victoria, Australia. Tel: \\ 61-3995-6128.
}

Received: October 2, 2020

Accepted: November 16, 2020

Online Published: December 7, 2020

doi:10.20849/aes.v5i2.814

URL: https://doi.org/10.20849/aes.v5i2.814

\begin{abstract}
This paper addresses challenges that arose during the on-going coronavirus pandemic and methodologies implemented in teaching a Biomechanics course in the Biomedical Engineering program (Biomedical and Electrical Engineering Discipline, Faculty of Engineering, RMIT University, Melbourne, Australia). We aimed to address the requirements for a quick transition of the entire curriculum to efficient remote delivery of the course, which involved: (i) providing authentic learning experiences; (ii) keeping students motivated and engaged with their classes and team projects; and (iii) preventing students from cheating when completing online assessments. The specific tools, software packages and approaches employed to support the remote teaching and learning are presented and discussed in this paper. Effective and on-going communication with students was crucial for managing their expectations, engagement with the course materials and teaching team, retaining positive learning experiences and for their overall well-being. The Socratic approach used in developing the online assessments was able to promote students' critical thinking, problem solving and self-reflection and assisted the teaching team in minimising online cheating.
\end{abstract}

Keywords: COVID-19, coronavirus pandemic, online learning, assessment, biomechanics, open-source software

\section{Introduction}

The design of the curriculum for the Biomechanics course was based on two pedagogical models: the interactive model (Sessoms 2008) and the collaborative discovery model (van Joolingen 2000), as shown in Figure 1.

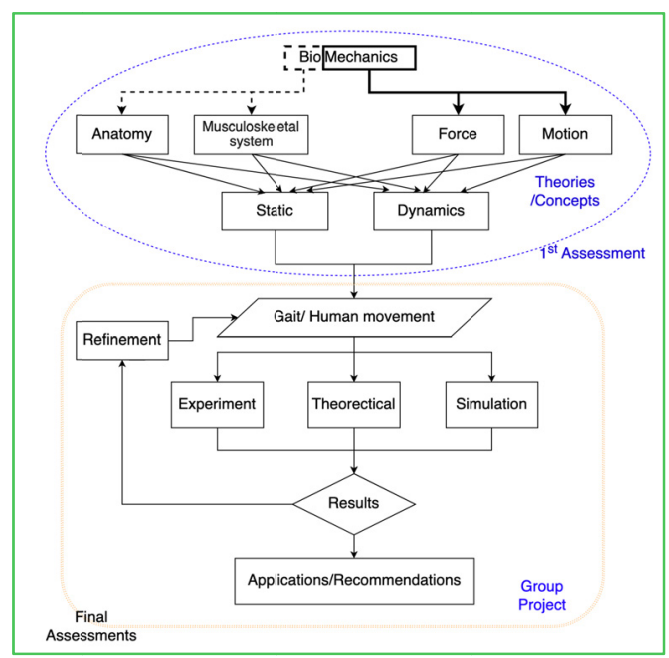

Figure 1. The pedagogic design used for a group work and problem-based learning: students first learnt biomechanics concepts through the weekly lectures, then used their knowledge to conduct group projects and, finally, to provide innovative solutions 
Using the interactive model, teaching staff encouraged students to participate in face-to-face learning activities during the delivery of key biomechanics concepts. These concepts had a particular focus on how the anatomy and musculoskeletal systems work in humans under different conditions, and to use force analysis and mechanics of human movements. Whereas, in the collaborative discovery learning, students were required to work in groups to solve real-life problems drawing on their own experience and key biomechanics concepts. The course included two individual assessments (mid-course and final) and one group assessment (the group assessment that included preparing a proposal).

Weekly lectures covered the following topics: force analysis and measurement, including clinical gait analysis; body segment kinematics; moment analysis of various joints; muscle mechanics; and principles of audio-feedback in human movement. Laboratory sessions were conducted in smaller groups to acquire knowledge and develop skills in using engineering software and analytical tools (such as Vicon Motion Systems and Nexus ${ }^{\mathrm{TM}}$ ) applied in biomechanics to assist in the development of the evaluation study.

The group project enabled the students to explore the extent to which audio-feedback, more specifically the auditory features in this feedback, informed human movement. This group project was designed as a training tool to enable students to: (i) conduct a gait analysis and apply key biomechanics concepts; (ii) determine the correlation between audio-biofeedback and movement; and (iii) apply appropriate biomechanical analysis to body movement.

The first class occurred on the $2^{\text {nd }}$ March 2020 with 28 undergraduate biomedical engineering students. They were divided into four groups and tasked with developing a new protocol for data collection as an important means of evaluating the correlation between audio-biofeedback and body movement. The conventional method for analysing human movement is to request participants to perform activities in the Biomechanics laboratory using motion capture systems. In this case, a total of thirty-five, $14 \mathrm{~mm}$, hard-based reflective markers were taped to the full body bony landmarks and segments as shown in Clark et al. (2016). A six-camera motion system (Vicon Motion Systems) captured the markers' movement at $120 \mathrm{~Hz}$. The associated software, Nexus ${ }^{\mathrm{TM}}$, was used to create the three-dimensional (3D) model of the human body and then analyse the movement and joint angles (Figure 2).

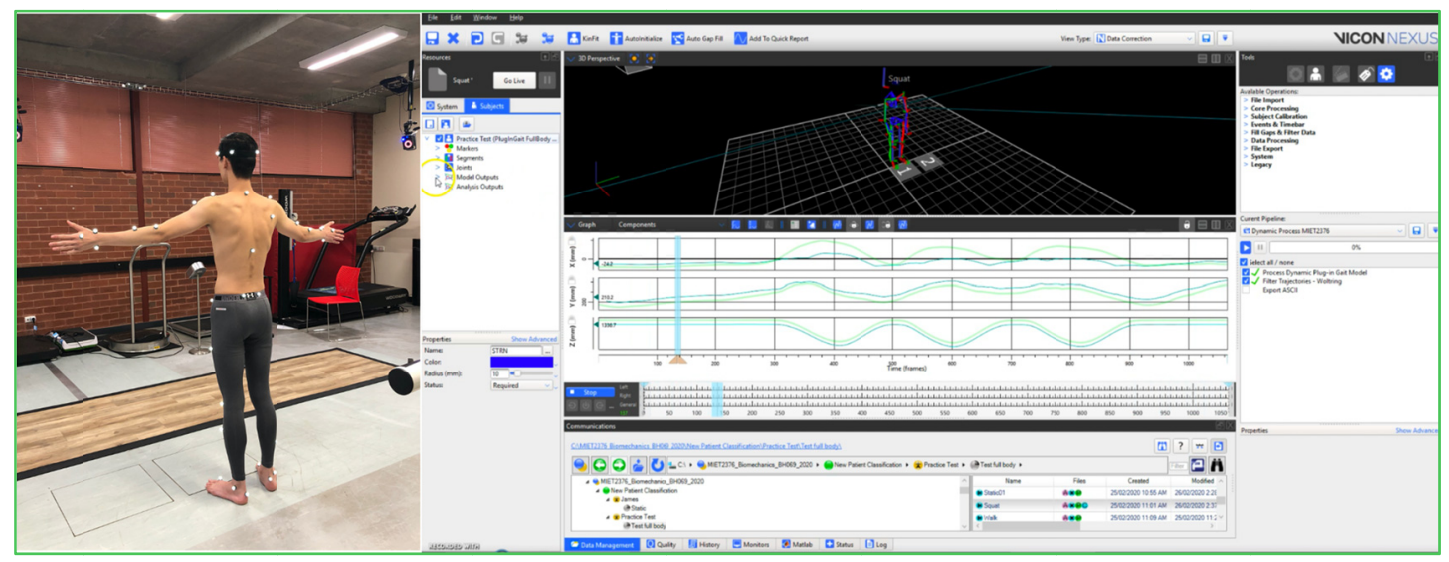

Figure 2. The set-up in biomechanics laboratory for human movement analysis

A total of 35 reflective markers were placed on specific anatomical landmarks on a participant. The movement was captured using Vicon Motion Systems, and the three-dimensional coordinates of the landmarks were reconstructed using the commercial Nexus ${ }^{\mathrm{TM}}$ software for performing movement analysis.

Before the pandemic, the teaching of Biomechanics course was performed in the conventional way using theoretical and laboratory face-to-face classes. In the theoretical classes (two hours per week over 12 weeks of the teaching semester), students were introduced to the fundamental concepts of the biomechanics of human body and movement. In the laboratory classes (four hours per session over ten weeks, with a maximum of 20 students in a given class), students had the opportunity to learn and use the Vicon System and Nixon ${ }^{\mathrm{TM}}$ software for movement analysis to conduct their experiments in a controlled environment.

However, due to the pandemic, since $23^{\text {rd }}$ March all lectures and laboratory sessions were no longer offered on 
campus. All teaching and learning activities were required to be delivered remotely via the internet using online collaboration platforms. This new course delivery format was required due to the Victorian state government-declared state of emergency that imposed social distancing and lockdown measures to stop the spread of the coronavirus. All face-to-face on-campus activities transitioned to online delivery mode.

\section{Objectives}

Teaching that aims to achieve high student satisfaction and successful learning outcomes is a very demanding task, especially after the onset of the pandemic. Universities all around the world have experienced massive disruption that has led to physical closure of campuses resulting in inability of students and staff to gain access to buildings and laboratories. All teaching and learning activities have transitioned to fully online delivery, which relies heavily on access to a computer or a tablet and, most importantly, on a reliable internet connection for each student. This requirement prompted our teaching team to develop agile plans and rapid responses to ensure the continuity of teaching and learning activities, while maintaining their quality and student engagement. The real challenge lay in adapting the usually heavy reliance on laboratory-based experiments to an online learning environment. We focused on developing an innovative approach enabling the traditional, laboratory-based, experimental learning to be conducted remotely by selecting the appropriate technologies and computational tools to train and engage students in working collaboratively and productively. This paper is reporting on the educational innovation and highlighting it characteristics, challenges and success.

The aims of this paper are to: (i) share our first experiences of the steps taken to deliver classes fully online; (ii) identify the challenges and successes based on these first experiences; and (iii) share students' feedback and learning outcomes. The paper begins with a description of the concepts underpinning the course curriculum. This is followed by reflections on the challenges, successes, motivations, outcomes and lessons learnt so far.

\section{Review of the Literature}

The unprecedented nature of the pandemic brought new challenges and disruptions to most, if not all, industry sectors. For the higher education sector, it changed the way academic staff teach and engage with students due to lockdown-induced campus closures as a result of the state government's strategy to suppress the transmission of the virus (Bao 2020; Bowen 2020). While the teaching activities such as lectures, tutorials, practical and assessments were predominantly delivered remotely in online mode, the pedagogical framework, learning quality and course learning outcomes remained unchanged.

The current study used the "student-centred learning" pedagogical approach to promote active learning, in which a mixture of lecturing, demonstration and rote learning activities were "visible" and structured, as well as being facilitated by the teacher (Jacobs and Renandya 2019). However, over the course of the online teaching sessions, a shift occurred in which the students became the centre of the activity and were expected to participate more actively in their own learning by interacting with peers and working together as a group (Baeten et al. 2015).

In order to complement successful active learning elsewhere (Sessoms 2008), a series of digital learning tools (e.g. hardware and software such as computers, overhead projectors, internet, YouTube, Kahoot! etc.) have been integrated by educators into the teaching and learning environment. Sessoms (2008) noted that integrating digital tools not only encouraged active participation in the learning process, but also assisted in the development of higher-order thinking skills as they analysed, synthesised and shared information and knowledge with peers.

In the earlier study, van Joolingen (2000) reported that when students were engaged in the process of sharing information and knowledge with each other, they were participating in collaborative learning. To cultivate collaborative learning, van Joolingen argued that students should work in small groups on problem-solving activities, in which they are required to formulate research questions, design experiments, understand analysis and interpret results. As reported previously (Kopp et al. 2014; Oxelmark et al. 2017; Pang et al. 2017), student need to develop effective peer communication and collaborative skills in order to achieve positive and high-quality learning outcomes.

Besides active and collaborative learning approaches, the key elements of this student-centred learning approach involve, but are not limited to, fostering a supportive learning environment with a focus on the enhancing learners' experiences, promoting deep learning, and understanding through engagement with knowledge derived from their life experiences, as well as applying ideas and information they encountered in problem solving in class and beyond the classroom (Jacobs and Renandya 2019; Sweetman 2017). These key elements of active and student-centred learning underpinned the approach we developed in the Biomechanics course to address the new challenges to existing pedagogy of fully remote and online teaching and learning that coronavirus pandemic thrust upon us. 


\section{Methodology}

The lecturing staff quickly modified the teaching strategies in order to enable a smooth transition to online learning. The strategies, specific tools and software used in the course delivery to support the online teaching and learning are described below.

\subsection{Data Collection}

This paper included only the third-year undergraduate students studying in Biomedical Engineering degrees in Semester 1, 2020, in which students take the Biomechanics course as one of their core courses. Student assessment results were analysed for frequencies and means using Excel. At RMIT University, there are student representatives who advocate for their peers and work with academic staff to consider concerns raised by students and highlight examples of good teaching practice. In this course, feedback from student representatives was collected during weeks 4 and 8 of the teaching semester. Students were invited to provide feedback on the teaching quality and their learning experiences in a course-experience survey that comprised two parts. The first part asked seven opinion-rating questions using a five-point Likert scale coded from 1 = "strongly disagree" to 5 = "strongly agree". The second part asked two open-ended questions to allow students to provide feedback on what worked well and what needed improvement in the course. The survey was conducted online between weeks 9 to 12 and their responses remained anonymous. Content Analysis was used to summarise students' feedback (Forman and Damschroder 2007).

\subsection{New Teaching Strategies}

While the content of the course remained the same as its face-to-face predecessor, the theoretical classes were changed to interactive problem-solving sessions conducted online. In order to make the learning online easier, the course coordinator (lead author) adopted a modular teaching framework (Guido 2014) by dividing the theoretical contents into small modules based on similar topics so that each module lasted for no more than 30 minutes.

The laboratory classes were changed to online interactive consultations with small group of students. As a result of these group consultations, students were able to engage with each other. The course coordinator's role was to facilitate discussion, provide advice and encourage the students in defining and framing the research problem, formulating the appropriate methodology and research questions, conducting their surveys, collecting data and, finally, analysing results. Each group consultation lasted for about 45-60 minutes.

In addition to these consultation sessions, the course coordinator also devoted considerable time to preparing videos on how to conduct movement analyses in home settings to facilitate students' learning experience.

\subsection{Collaborate Ultra and Kahoot!}

As a result of these changes and challenges, we used a real-time video conferencing tool, Collaborate Ultra to deliver the online lecture. The tool is embedded in Canvas (a learning management platform). It allows users to add files, share applications and use a virtual whiteboard to deliver the online lectures as well as conduct online consultations with students. It also allows the classes to be recorded so students could catch up on missed teaching. All these features were used during online delivery of the Biomechanics course.

The course coordinator also incorporated Kahoot to boost class interaction and promote active learning during the online classes. Kahoot is a free, game-based, learning platform that allows lecturers to create their own quizzes and include images to enhance teaching of and learning by using their personal devices and entering a game PIN. During the lecture, the Kahoot quizzes were shared with students and students reported having fun when participating in the online quizzes. Kahoot quizzes were used as a formative assessment to enable the lecturer to collect data and analyse the questions or concepts that students were struggling with and then devise a plan aimed at improving students' learning.

\subsection{Redesigning Home-Based Experiment}

To reinforce the experimental learning and group work, we also modified the group project to enable students to carry out their research and data collection in their homes. As students had continuous access to the powerful tools of internet, media, and smart devices equipped with the sophisticated cameras, we leveraged their capacity to use their own devices to record human movement in a home setting. For those who were facing financial hardship and did not have suitable technology, RMIT University provided an additional Technology Grant (up to AU $\$ 1,000)$ to assist students with purchasing essential equipment (including hardware, software and digital material) to continue their studies remotely. 


\subsection{Project in Action}

To start, each group was required to develop a research objective based on the broader evaluation of audio-biofeedback and style movements for their project. They then needed to consider a protocol (including sample size, participant characteristics, inclusion and exclusion criteria) for data collection and analysis. In order to achieve their objective, they were asked to discuss and formulate research questions and hypotheses to test and assess body movements in relationship to audio-biofeedback. Both quantitative measurements and qualitative descriptions play important roles in the analysis of human movement. Therefore, students were advised to discuss what type of measurements to employ and what questions to ask their participants when collecting data.

To collect relevant demographic and qualitative data, students were tasked with developing their own questionnaires for participants. As the group projects involved human participants, students were advised to" (i) discuss the ethics of responsible human research; (ii) determine whether there are any potential risks associated with participation in the projects; (iii) explain the activities that potential participants would be required to undertake; and (iv) obtain participants' consent prior to engaging in any activities.

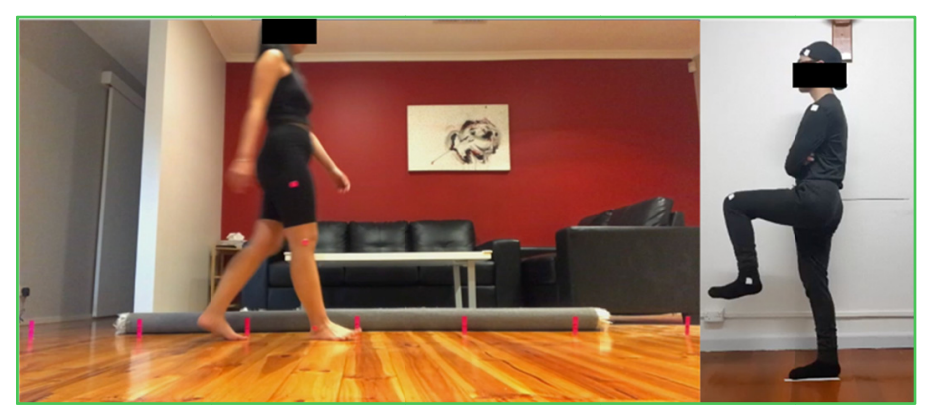

Figure 3. Simplified reflective tape markers for human movement analysis at home

For the quantitative part of the research, students were advised to use reflective tape as markers to place on participants to determine the range of motion of body segments such as the hip, knee and ankle joint, as shown in Figure 3. Students then utilised video cameras on their smart phones or tablets to capture the motion of the participants. If students did not have a smart phone, they were provided with a video camera for the recording of a motion. Students were also advised to consider potential parallax and perspective errors due to placement of the camera.

\subsection{Kinovea for Motion Analysis}

Kinovea is free, open-source software for sports analysis. This software is straightforward and easy to use. The students can upload videos, select the markers in one frame, and then Kinovea will track the markers and allow the students to measure lengths and angles frame by frame, and compare the measurements (Figure 4).

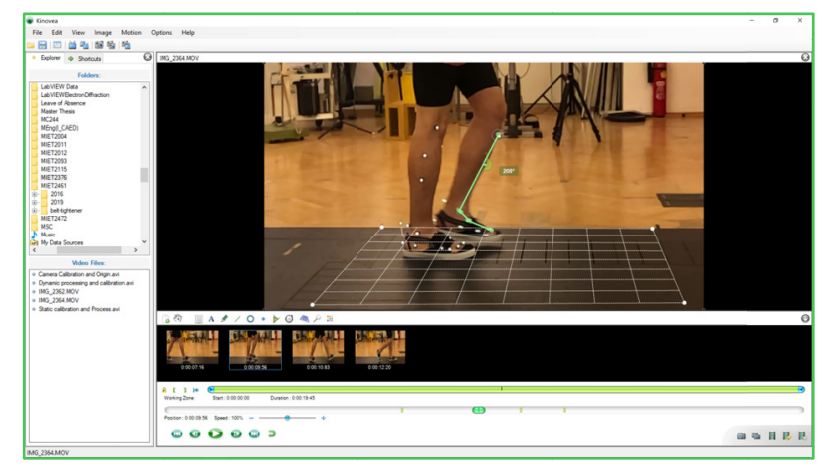

Figure 4. Open-source Kinovea software for motion analysis with which users can easily select anatomical locations and measure joint angles 


\subsection{Max Digital Sound Software for Audio-Biofeedback}

The original course plan had been to develop an audio-biofeedback platform that focussed on movement features, for example, left and right leg rhythm when walking, using the Max 8 digital sound prototyping software. This software patch was developed by the second author to take recorded Vicon motion data as input to drive the sonic features of the audio-biofeedback. However, after the onset of the pandemic, the project changed to a series of sound recordings generated from walking and standing movement data captured earlier in a laboratory. These recordings were distributed to the student groups to use as a guide in the movement activity and to observe the effects in the student-led experiments they conducted at home. Similar approaches have been used to provide constant tempo to guide repetitive actions such as walking (Maculewicz et al. 2015), thus, we were confident that, while these data were on pre-recorded human movement, they would serve to facilitating the students' own studies.

\subsection{Innovative Online Assessments}

Initially, the course assessments were developed to be undertaken by students on campus under the watchful eyes of invigilators. However, due to the pandemic, students had to undertake their assessments online. We were aware that some students at times outsource or upload their assessments online and pay for solutions (Bretag et al. 2019). In designing new online assessments, we had to consider how effectively and authentically we could assess students' skills and knowledge while minimising cheating. In order to mitigate cheating, the course coordinator adopted the following approaches for online assessments: (i) using conceptual questions based on the Socratic approach that required students to state the assumptions, discuss reasons and provide evidence (Delic and Bećirović 2016); (ii) using personal data such as unique student numbers and anthropometric data for problem-solving questions; and (iii) setting a time limit, e.g. 90 minutes, for students to attempt all questions. An example of the conceptual question is shown in Figure 5.

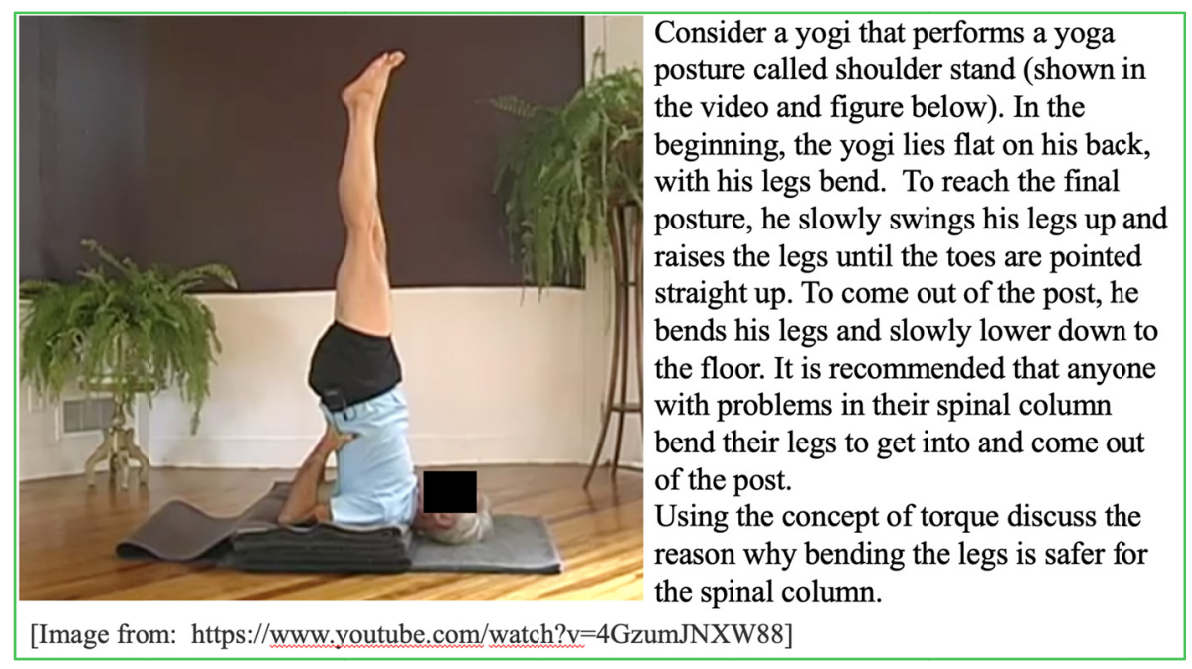

Figure 5. Sample assessment question using the Socratic approach to minimise cheating and to assess authentic students' understandings of key biomechanics concepts

\section{Results and Discussion}

The coronavirus pandemic and closure of Australian borders to international travel impacted on international students, affected domestic students and reduced overall enrolment numbers. Three overseas students were not able to travel back to Melbourne, two onshore international students faced financial hardship and decided to discontinue with the course, and one local student took leave of absence due to work commitments. Hence, a total of 22 students were included in this paper.

\subsection{Student Feedback}

We progressively examined all tasks performed by the students and were able to receive their feedback throughout the semester to evaluate the innovative teaching approaches in which students were expected to demonstrate the acquired course learning outcomes and competences.

For the first two weeks of the transition period, there were concerns with the group project work. Students found 
that the group projects a challenge and were confused about the required tasks and how to continue their studies at home without the necessary equipment. Students required more explanation of laboratory work to ease their anxieties. We took note of the students' concerns and the course coordinator quickly set up a discussion board on Canvas for students to post their queries and to provide them with direct answers quickly and efficiently. This approach worked well to support students' learning and general wellbeing.

In relation to the online survey, students stated that the online quizzes via Kahoot helped them improve their learning. As one student noted:

I really like the way the lectures were delivered at the start of the semester with the Kahoot encompassing the whole lecture and the expectation that we study the content before the lecture. I really felt that having the practice quizzes and doing questions helped me learn a lot.

Another student reported that the integration of quizzes into the online tools helped with grasping key biomechanics concepts better:

Learning about the mechanics of the body and how they work. The way [the lecturer] was able to integrate the class into online learning all the quizzes that were provided for learning.

Overall, the students' collective feedback for the course was very positive. They reported that the lecture and tutorial sessions were interesting and engaging. Staff flexibility and fast responses to change and adjust assignments for working at home was greatly appreciated by the students. Students also found that the Kahoot quiz engaging and fun and the online tutorials were appreciated and highly beneficial for their learning. This result is consistent with the earlier report by Sessoms (2008).

\subsection{Group Project}

The authors developed the new group project to support students working remotely on the project and provide them with challenging, hands-on experiences that augmented their research and education in the biomechanics field. Students worked collaboratively to perform different experiments, which was essentially a process of problem solving, formulating research questions and preparing technical reports, and then interpreting and justifying their findings related to the assigned project task.

As those students were studying remotely, we improvised to leverage technology use outside the classroom to capture human movement and replace the Vicon Motion Systems used in the laboratory. Students were advised to use their personal devices and open-source software to conduct the home-based experiments and to interact with peers and the course coordinator to keep them stimulated and engaged. With this work-a-round approach, we saw students taking a more active role and pride in their learning as they adapted to problem-solving tasks with the tools and materials that they had to hand. The online team consultation sessions were important for the course coordinator to connect with students, support their engagement, stimulate motivation, provide feedback, assist with problem solving, improve technical competency, foster team collaboration skills, and build confidence.

Based on the proposals and final reports submitted by the student groups, it was clear that they demonstrated the necessary skills in developing the research instruments (such as questionnaires, consent forms and risk assessments) required for conducting the research tasks safely and minimising foreseeable risks. As reported (Kopp et al. 2014; Oxelmark et al. 2017; Pang et al. 2017), developing the capacity to work as a team member is a crucial outcome of incorporating group-based projects into an active learning environment. Most students in this course did demonstrate improved capabilities in working as effective team members, which enabled them to complete their projects to the highest standard. They also learned to adhere to ethical principles in order to protect the rights and welfare of their research participants. The more advanced groups proposed several hypotheses that addressed different aspects of their research questions. They also performed simple statistical analyses such as the student $t$-test for the comparison of more than two independent samples. In future implementation, we will encourage students to be more curious about the data they collected and initiate further statistical analyses to examine their datasets in more detail.

We discovered that the home-based experiments had two main challenges: (i) student groups that lack good learning attitudes and were disorganised (e.g. a lack of time management skills and inexperience in studying in-depth or grappling with breadth of the course content) often ended up with poorer grades; and (ii) experiments conducted in individual homes, not in a controlled laboratory environment, produced some inconsistencies. As one of the groups indicated in its report:

Some of these inconsistencies included camera angles and placement of the camera. Since the cameras had to be set up manually for each person, the angle might have had a slight distortion which might have caused the 


\section{parallax error.}

However, what we tried was the "next best approach" enabling students to conduct human movement analysis remotely, compared with commercially available systems in the laboratory, while still achieving the course's learning outcomes. Although the group project tasks were demanding and time-consuming, they challenged the students effectively and encouraged them to work together, leading to innovative techniques for analysing data and gaining new insight into the relation between gait and audio-biofeedback.

\subsection{Online Assessments}

The assessments were developed with the aim of providing authentic experience to students and to minimise the incidence of online cheating. Socratic questioning - the act of asking questions in order to prompt critical thinking and reflection - and using authentic scenario-based problems have been shown to be effective for measuring students' learning and their application of acquired knowledge to various biomechanical problems. The distribution of student results showed the approach worked well (Figure 6). The average grade for the first and final assessments was 9 out of 15, and 22 out of 30, respectively. Some students did find it difficult to apply their understanding of biomechanical concepts to problem solving. For example, in the sample assessment question described in Figure 5 above, students were required to apply the concepts of torque and force to solve the problem of ensuring safer movement in relation to spinal column problems. Subsequently, we recognised that students needed to be pointed towards these concepts. The use of online assessments, involving complex problem solving, clearly improved the authenticity in learning but, as reported previously (Pang et al. 2017), the introduction of online assessments can be challenging due to different technical issues such as unstable networks, slow computers and hardware compatibility. Hence, online assessments need to be properly and thoughtfully implemented to support student learning (Wibowo et al. 2016), and several technological challenges require further research in order to optimise their use in the improvement of student learning.

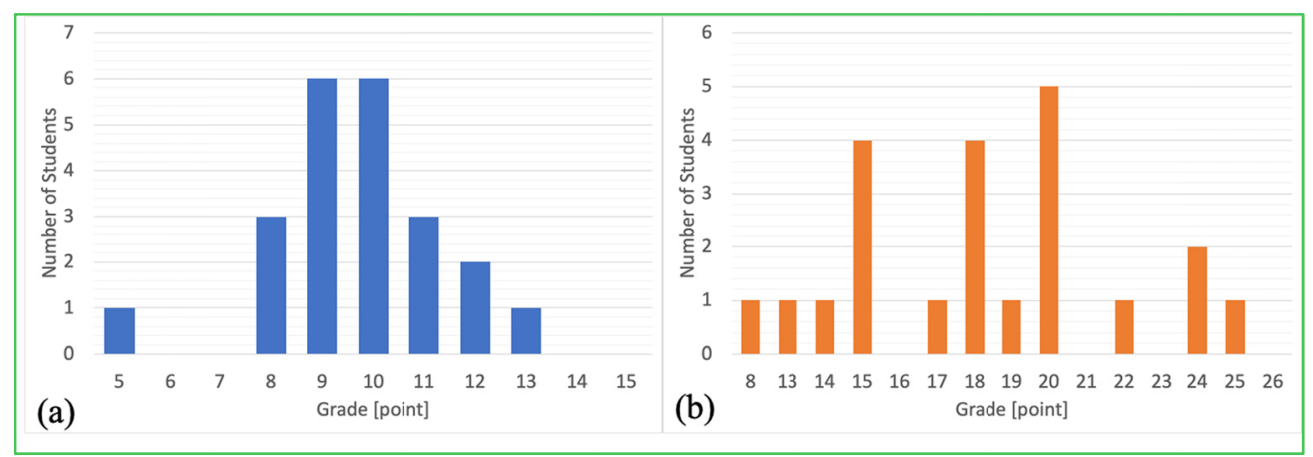

Figure 6. Student results distribution on assessment tasks: (a) mid-course assessment, (b) final assessment, which demonstrates that the online assessment did not skew the result toward higher grades

\section{Conclusions}

This paper addresses the challenges of transitioning from traditional, laboratory-based, human movement experiments in teaching Biomechanics in remote learning environments during the coronavirus pandemic. These challenges were addressed by choosing the right technologies and approaches to encourage students to work collaboratively and effectively. We leveraged the students' personal devices and open-source software to enable them to continue their experiments and to learn remotely. The group project helped students stay connected and work together. This approach motivated students' engagement and led them to employ innovative methods for data analysis and develop new insights into understanding the relation between gait and audio-biofeedback. Students found the online quizzes using Kahoot tool engaging and fun, and the online tutorials were appreciated and highly beneficial for learning biomechanical concepts and developing their knowledge. Continuous communication with students during the semester and use of discussion boards embedded in the learning management platform (Canvas) were important for keeping students informed and supporting their learning.

\section{Acknowledgements}

The authors would like to acknowledge their higher education institution and all the students who volunteered to collaborate in this paper. 


\section{References}

Baeten, M., Dochy, F., Struyven, K., Parmentier, E., \& Vanderbruggen, A. (2015). Student-centred learning environments: an investigation into student teachers' instructional preferences and approaches to learning. Learning Environments Research, 19(1), 43-62. https://doi.org/10.1007/s10984-015-9190-5

Bao, W. (2020). COVID-19 and online teaching in higher education: A case study of Peking University. Human Behavior and Emerging Technologies, 2(2), 113-115. https://doi.org/10.1002/hbe2.191

Bowen, M. (2020). Covid-19 has changed how we teach students. The Veterinary Record, 186(14), 461. https://doi.org/10.1136/vr.m1535

Bretag, T., Harper, R., Burton, M., Ellis, C., Newton, P., Rozenberg, P., ... Van Haeringen, K. (2019). Contract cheating: a survey of Australian university students. Studies in Higher Education, 44(11), 1837-1856. https://doi.org/10.1080/03075079.2018.1462788

Clark, C., Barnes, C., Holton, M., Summers, H., \& Stratton, G. (2016). A Kinematic Analysis of Fundamental Movement Skills. Sport Science Review, 25, 261-275. https://doi.org/10.1515/ssr-2016-0014

Delic, H., \& Bećirović, S. (2016). Socratic Method as an Approach to Teaching. European Researcher, 111, 511-517. https://doi.org/10.13187/er.2016.111.511

Forman, J., \& Damschroder, L. (2007). Qualitative Content Analysis. Emerald Group Publishing Limited. https://doi.org/10.1016/S1479-3709(07)11003-7

Guido, R. M. D. (2014). Evaluation of a Modular Teaching Approach in Materials Science and Engineering. American Journal of Educational Research, 2(11), 1126-1130. https://doi.org/10.12691/education-2-11-20

Jacobs, G. M., \& Renandya, W. A. (2019). Student Centered Cooperative Learning: Linking Concepts in Education to Promote Student Learning. Singapore: Singapore: Springer Singapore Pte. Limited. https://doi.org/10.1007/978-981-13-7213-1

Kopp, B., Hasenbein, M., \& Mandl, H. (2014). Case-based learning in virtual groups - collaborative problem solving activities and learning outcomes in a virtual professional training course. Interactive Learning Environments, 22(3), 351-372. https://doi.org/10.1080/10494820.2012.680964

Maculewicz, J., Jylhä, A., Serafin, S., \& Erkut, C. (2015). The effects of ecological auditory feedback on rhythmic walking interaction. IEEE Multimedia, 22. https://doi.org/10.1109/MMUL.2015.17

Oxelmark, L., Amorøe, T. N., Carlzon, L., \& Rystedt, H. (2017). Students' understanding of teamwork and professional roles after interprofessional simulation-a qualitative analysis. Advances in Simulation, 2, 1. https://doi.org/10.1186/s41077-017-0041-6

Pang, T. Y., Kootsookos, A., Steiner, T., Khatibi, A., \& Crossin, E. (2017). Collaborative project: exploring the experiences of engineering students' engagement in face-to-face and virtual peer learning. Journal of Modern Education Review, 7(3), 185-196.

Sessoms, D. (2008). Interactive instruction: creating interactive learning environments through tomorrow's teachers. International Journal of Technology in Teaching and Learning, 4(2), 86-96.

Sweetman, R. (2017). HELOs and student centred learning - where's the link?. European Journal of Education, 52(1), 44-55. https://doi.org/10.1111/ejed.12202

Van Joolingen, W. R. (2000). Designing for Collaborative Discovery Learning. Intelligent Tutoring Systems, 5th International Conference, ITS 2000, Montréal, Canada. https://doi.org/10.1007/3-540-45108-0_24

Wibowo, S., Grandhi, S., Chugh, R., \& Sawir, E. (2016). A pilot study of an electronic exam system at an Australian University. Journal of Educational Technology Systems, 45(1), 5-33. https://doi.org/10.1177/0047239516646746

\section{Copyrights}

Copyright for this article is retained by the author(s), with first publication rights granted to the journal.

This is an open-access article distributed under the terms and conditions of the Creative Commons Attribution license (http://creativecommons.org/licenses/by/4.0/). 